\title{
MEMÓRIA E AFETO: UMA TRAJETÓRIA SOBRE A REPRESENTAÇÃO DO AMOR NA VELHICE EM OLHOS DE RESSACA
}

\author{
MEMORY AND AFFECTION: A TRAJECTORY ON THE REPRESENTATION \\ OF LOVE IN OLD AGE IN OLHOS DE RESSACA
}

\section{MEMORIA Y AFECTO: UNA TRAYECTORIA EN LA REPRESENTACIÓN DEL AMOR EN LA VEJEZ EN OLHOS DE RESSACA}

\author{
Clarissa Raquel Motter Dala Senta \\ Mestre, Universidade Federal de Goiás \\ clarissamotter@hotmail.com \\ Maria Luiza Martins de Mendonça \\ Doutora, Universidade Federal de Goiás \\ mluisamendonca@gmail.com
}

\begin{abstract}
A morte e o amor. Por que o amor, como a morte, também existe - e da mesma forma dissimulada. Por trás, inaparente. Mas tão poderoso que, da mesma forma que a morte - pois o amor é uma espécie de morte (a morte da solidão, a morte do ego trancado, indivisível, furiosa e egoisticamente incomunicável) - nos desarma.

Caio Fernando de Abreu
\end{abstract}

\section{Resumo}

Este trabalho faz parte de uma pesquisa mais extensa sobre a representação da velhice e do envelhecimento no cinema brasileiro contemporâneo e tem como objetivo contribuir para uma melhor compreensão das relações entre comunicação audiovisual e (re) produção de discursos afetivos. Parte-se do princípio que as sociedades contemporâneas têm aberto espaços para a expressão de novas polaridades identitárias na representação das relações amorosas na velhice, nas quais a memória e os afetos despontam como potências libertadoras e transgressoras, sobretudo para o feminino. No intuito de realizar uma reflexão pontual, desenvolve-se a Análise Fílmica do curta-metragem Olhos de Ressaca, demonstrando que outras formas de manifestação simbólica das afetividades apontam para uma ressignificação do ideário de amor romântico entre os corpos envelhecidos.

Palavras-chave: Cinema. Envelhecimento. Relações amorosas.

Esta obra está licenciada sob uma Licença Creative Commons 


\begin{abstract}
This work is part of a more extensive research on the representation of old age and aging in contemporary Brazilian cinema and and aims to contribute to a better understanding of the relationship between communication audiovisual and (re) production of affective speeches. Starts from the principle that contemporary societies have open spaces for the expression of new identity polarities in the representation of romantic relationships in old age, through which memory and affections emerge as transgressive and liberating powers, especially for females. In order to conduct a timely reflection, develops the film analysis of the short film Olhos de Ressaca, showing that other forms of symbolic expression of affectivity point to a redefinition the ideals of romantic love between bodies aged.
\end{abstract}

Keyword: Cinema. Aging. Relationships

\title{
Resumen
}

Este trabajo forma parte de una investigación más amplia sobre la representación de la vejez y el envejecimiento en el cine brasileño contemporâneo y tiene como objetivo contribuir a una mejor comprensión de la relación entre comunicación audiovisual y (re) producción del discursos afectivos. El principio es que las sociedades contemporáneas tener espacios abiertos para la expresión de nuevas polaridades de identidad en la representación de las relaciones románticas en la vejez, a través del cual la memoria y losafectos emergen como potencias transgresoras y liberadoras, en especial para las mujeres. Con el fin de llevar a cabo una reflexión puntual, desarrolla el análisis fílmica del cortometraje Olhos de Ressaca, mostrando que otras formas de manifestación simbólica de la afectividad apuntan a una redefinición de la noción de amor romántico entre los cuerpos envejecidos.

Palabras-clave: Cine. Envejecimiento. Relaciones románticas.

\section{INTRODUÇÃO}

A representação do universo dos mais velhos no cinema brasileiro, sobretudo após o período da Retomada ${ }^{1}$, tem lançado outros sentidos sobre os processos de envelhecimento, sentidos esses que imprimem olhares diversificados a respeito das relações afetivas na velhice. Percebe-se, a partir desses olhares, uma tendência em rever estereótipos que se construíram ao longo do tempo, responsáveis por associar a idade avançada à solidão e à dependência ou - em um sentido oposto, mas complementar - por reproduzir uma busca

\footnotetext{
${ }^{1}$ O cinema da Retomada, ou "renascimento do cinema brasileiro" ou "novo cinema brasileiro", nasceu do resultado das leis de incentivo promulgadas a partir de 1992 e que impulsionaram o cinema brasileiro, sobretudo a partir de 1994. De acordo com Mattos (1998), o cinema que temos hoje surgiu a partir da descompressãopolítica resultante da derrocada moral e legal do governo Collor, do advento de leis de incentivo eficazes e da entrada no meio cinematográfico de realizadores advindos de outras áreas, tais como teatro, produção musical, vídeo e curta-metragem.
} 
frenética pela eterna juventude, característica da contemporaneidade, e que traz como pressuposto para a realização amorosa a manutenção do corpo jovem.

Em contraposição a essas visões, narrativas cinematográficas têm retratado a chegada do envelhecimento como um momento adequado a novas vivências, no qual as experiências vividas e os saberes acumulados são ganhos que oferecem oportunidades de estabelecer relações mais profícuas com os mais jovens e com os mais velhos (DEBERT, 1999a). Transpostas e (re) construídas para as telas de cinema, essas novas possibilidades de vivências na velhice podem oferecer outras leituras sobre o amor, sobre a sedução e sobre o feminino, especialmente por meio da valorizaçãoda memória e dos afetos (entendidos aqui como capazes de incitar a ação e a mudança).

Assim, segundo Montoro (2009), a expressão visual de novas polaridades identitárias sobre os processos de maturidade tem apontado para novos protagonismos sociais que orientam para um olhar mais plural e multifacetado a respeitodo envelhecimento. Isso reflete um meio sociocultural heterogêneo, onde a multiplicidade de estímulos aos quais estão submetidos os indivíduos nas sociedades contemporâneas permite, também, que estes tenham uma elevada consciência de suas subjetividades, se recusando a agir de forma homogênea aos apelos externos (BARROS, 1987). A partir dessa perspectiva, convivem, então, estilos de vida, visões de mundo e representações sociais distintas.

É nesse sentido que, ainda segundo Barros (1987), a coexistência de diferentes campos simbólicos na discussão sobre as representações sociais destaca um espaço de escolha aberto aos agentes sociais, espaço esse onde os atos conscientes do indivíduo e sua experiência de vida constituem pontos relevantes. "O sistema de signos de cada cultura é visto nesse quadro teórico como um código das experiências dos indivíduos, expressivo e interpretativo de uma realidade, capaz de ser traduzido e comunicado” (BARROS, 1987, p.30).

Portanto, ao apropriar-se desse sistema de signos, a comunicação audiovisual expressa, produz e reproduz um universo simbólico que reflete e afirma não só a permanência, mas também a mudança, não só o reforço, mas também a subversão em relação a práticas socioculturais instituídas. Tendo em vista o objeto de estudo da Comunicação como formado por práticas comunicacionais liberadas pela sociedade, práticas essas “contextualizadas em um certo tipo de organização social e que têm no emprego dos meios de comunicação sua expressão mais constante e evidente” (MARTINO,2001, p.74), confirma-se, assim, a importância do estudo do cinema como (re) produtor da realidade. 
Ao partir, então, das complexas relações entre representações sociais e produção de sentidos na comunicação audiovisual, ancoradas na coexistência de eixos simbólicos distintos, é que se pode perceber a emergência de narrativas cinematográficas que subvertem um modelo familiar orientado por práticas patriarcais - no qual há uma dominância do olhar masculino sobre o feminino - modelo esse que incide na edificação dos relacionamentos amorosos. Corroborando as entrevistas realizadas por Barros (1987), essas novas narrativas têm partido do conceito de família como um grupo de pessoas que, unidas pelos laços do parentesco e da afinidade, estabelecem entre si códigos próprios capazes de fazer fluir inúmeras facetas de relacionamento.

Esses códigos trabalham, muitas vezes, na construção de um tempo biográfico que ressignifica as experiências pessoais e afetivas na velhice. Como contraponto à fuga do envelhecer corporal, aos apelos emocionais efêmeros e à submissão e/ou vitimização feminina nas relações amorosas, apresenta-se então abordagens cinematográficas alternativas, nas quais as trajetórias de vida e as afetividades aparecem como possibilidades de diálogo entre os gêneros, como novas formas de lidar com as questões de vida e morte e como potências libertadoras, sobretudo para a mulher.

Em meio às obras nacionais contemporâneas que retratam a heterogeneidade dos sentidos afetivos entre os mais velhos, o curta-metragem Olhos de Ressaca ${ }^{2}$ destaca-se, então, em sua abordagem narrativa (que transita entre antigos arquivos de família, imagens recentemente captadas e paisagens extra-diegéticas), (re) construindo, de forma experimental e poética, a biografia e a trajetória amorosa do casal Vera e Gabriel. A obra apresenta-se, assim, como um exemplo significativo dentro da temática e enfoque aqui propostos, tendo sido, por isso, escolhida para acompanhar as reflexões desenvolvidas neste artigo.

Porém, antes de aprofundar-se nesse exercício analítico e reflexivo, traça-se um breve panorama sobre o amor como fenômeno histórico, social e cultural, fenômeno este que ressoa na construção cinematográfica dos discursos amorosos e das experiências romântico-afetivas na velhice.

\footnotetext{
2 Produzido pela Aruac Produções, em 2009, Olhos de Ressaca foi lançado fora do circuito comercial, tendo sido selecionado e exibido em festivais nacionais e internacionais e premiado, no ano de 2009, como melhor curta-metragem no Festival do Rio, no London International Documentary Festival e no Festival Internacional Cine Las Américas. Recebeu também o prêmio especial do júri no Festival de Gramado. O filme é a estréia de Petra Costa na direção, antropóloga formada também em teatro pela Columbiua University.
} 


\section{DESENVOLVIMENTO}

\subsection{Representações do amor no curso do tempo: da prescrição à subversão afetiva}

Sob a perspectiva das ciências sociais, o estudo das afetividades é de importância primordial para que se melhor compreenda as diversas organizações sociais e culturais, já que são as articulações afetivas que se estabelecem dentro de cada sociedade que definem aquilo que é adequado ou não, desejável ou não nas relações entre os indivíduos.

Em uma apreciação do trabalho do autor alemão Niklas Luhmann, Neves (2007) corrobora essa visão e enfatiza o amor como fenômeno histórico a partir do qual não há razão para o sentimento acontecer senão incorporado em um código social partilhado por indivíduos que se relacionam entre si. Indo além, a autora coloca ainda que o amor estabelece-se como um veículo de comunicação simbólica devendo, portanto, ser entendido como um código de comunicação que forma, expressa, simula e atribui sentidos às relações sociais. Esse código, no entanto, não é fixo. Está, sim, relacionado à ação social, permitindo também, por decorrência, a criação de novas relações sociais. O amor é assim um construto social que se apresenta de forma específica em função das diversas culturas existentes e/ou de distintas temporalidades.

É entendendo, então, as afetividades como produtoras, reprodutoras e interpretativas de nossas experiências históricas e culturais que se torna possível avançar para o entendimento do amor como um produto social e, consequentemente, como um produto discursivo. Essa perspectiva torna-se importante quando se trata de investigar a transposição das relações amorosas para o cinema, entendendo-se que "as histórias que construímos e que contamos sobre o amor fazem parte de uma matriz cultural e, nessa medida, são histórias únicas de um lugar e de uma época peculiar, acabando por ter uma função social reguladora.” (NEVES, 2007, p. 612). Em outras palavras, ao (re) produzir narrativas sobre o amor, o cinema, como significante veículo de comunicação, orienta, dentro de determinado tempo, sociedade e cultura, quanto às relações nas quais devemos ou não investir.

Nesse sentido, ancorada em pressupostos elegidos nos séculos XVIII e XIX para a constituição da família burguesa e patriarcal, a representação do ideário do amor romântico volta-se ainda, e muitas vezes, para as seguintes prerrogativas: casamento, procriação, perpetuação da família, manutenção geracional, mulher submissa ao papel de mãe e esposa e liberdade social e sexual do homem (GUEDES;ASSUNÇÃO, 2006). Essas prerrogativas 
implicam a naturalização de uma hierarquia onde o homem adquire uma posição superior em relação à mulher. O casamento configura-se, assim, como elemento legitimador dessa diferença "natural”.

Decorre desse ponto de vista a construção de estereótipos que restringem a realização amorosa feminina ao casamento e à maternidade, atestando, mesmo que implicitamente, uma certa submissão de um gênero (o feminino) ao outro (o masculino). Sobretudo com o avanço da idade, a representação do feminino nas produções cinematográficas tende a orientar para o papel de “esposa-mãe” em contraposição aos estereótipos da "viúva” ou "solteirona”, tidos como negativos. O amor é assim representado como uma troca desigual (entre um "superior" e um “inferior”), tendendo a fixar determinados comportamentos considerados adequados e desejáveis e a excluir formas diferenciadas de exercício do afeto.

Esse modelo representativo que encontra suas raízes em valores patriarcais ainda persistentes combina-se, por vezes, às transformações sociais e culturais características da contemporaneidade. Assim, o individualismo, o desapego e uma maior liberdade nas relações, apontam para indivíduos instáveis que estabelecem relações afetivas cada vez mais frágeis, fundadas e desfeitas na obtenção ou não de gratificações imediatas. Dentro desse contexto, os relacionamentos amorosos tendem a se adequar à lógica do consumo, tornando-se produtos tão descartáveis quanto a roupa que não mais está na moda ou o celular que se torna obsoleto. Ainda dentro dessa perspectiva, o corpo (sobretudo o feminino) adquire valor primordial, sendo consumido e tratado tal como um "software" que deve ser constantemente "atualizado", reformado, rejuvenescido, para que possa então se adequar aos requisitos de uma realização amorosa que pressupõe beleza padronizada, juventude física e aprovação masculina. Assim, as relações romântico-afetivas são normalmente representadas no cinema por meio de corpos jovens, ilusoriamente perfeitos, férteis, apresentando-se os corpos envelhecidos como destituídos de atrativos, de romantismo e de beleza.

Aparentemente paradoxais, valores patriarcais e valores contemporâneos convivem, então, em narrativas audiovisuais que adaptam o ideário do amor romântico tradicional baseado no casamento e na construção de uma família patriarcal - à lógica imediatista do consumo, que recusa o velho, o envelhecimento, o corpo que não é mais capaz de procriar, a memória e a permanência em uma tentativa de dominação masculina velada.

No entanto, se prerrogativas contemporâneas podem convergir para a representação de relações amorosas desiguais, combinando-se aos valores tradicionais, podem também, por 
outro lado, trabalhar em sentido contrário, demonstrando - conforme a análise de Neves (2007) sobre os conceitos elaborados por Giddens - a transição do modelo de "amor romântico” para o “amor confluente”.

Essa transição está diretamente associada com as transformações operadas no estatuto social das mulheres, transformações essas que decorrem da exigência de homens e mulheres partilharem relações íntimas igualitárias. O "amor confluente" diz respeito então à tendência para um comprometimento afetivo e emocional igualitário entre os sexos (NEVES, 2007, p. 620).

Ainda segundo a autora, essa contribuição evidencia a emergência de discursos e práticas sociais alternativas que repõe a possibilidade de uma consciência social mais comprometida com os valores da igualdade. Aqui o amor é considerado com um "motor de ação social” que permite construir novas relações sociais.

Nessa realidade, o resgate dos valores afetivos combinados a uma maior liberdade pode subverter tanto uma lógica patriarcal ainda presente de forma velada, como uma lógica consumista/imediatista característica dos tempos atuais. Ressignifica-se, assim, o amor romântico no diálogo entre os gêneros, na efetiva interação do “eu” com o “outro” e na valorização da memória. O amor que aqui sobressai é o amor conquistado com o tempo, exercitado na convivência, na aceitação de si mesmo e do outro, no respeito por si mesmo e pelo outro. É o amor que cresce a partir da igualdade, mas que também afirma diferenças: no encontro dialógico de subjetividades, na construção singular de uma relação amorosa que se evidencia na criação de códigos distintos dos convencionais.

Nesse sentido, Costa (2005) coloca que, embora a sociedade de consumo, a indústria do entretenimento e o advento de novas tecnologias forneçam bens e serviços necessários aos rituais romântico-amorosos - e que proveem subsídios para a realização de um amor romântico idealizado, orientando quanto àquilo que deve permear ou não os relacionamentos afetivos - o que define a relação amorosa como tal não é o consumo desses rituais, mas o estabelecimento de uma comunicação pessoal que confirme as diferenças individuais.

Assim, para o autor

É a existência dessa forma particular de comunicação - o código do amor que define a conformação do mundo especial dos amantes, no qual os rituais e adereços românticos adquirem sentido efetivo, concretizando sua vocação amorosa. É ativação desse código especial, e não o preço do item escolhido no cardápio, que diferencia aquele casal que no restaurante francês, à luz de velas, vive seus estados amorosos liminares daquele outro casal presente no mesmo restaurante sob a mesma penumbra, mas que não se ama, apenas se entretém (COSTA, 2005, p.6). 
O que se destaca, aqui - e o que abre espaço para a construção de relações afetivas libertárias e mais sólidas - são as diversas formas de apropriação dos bens materiais e simbólicos disponíveis aos amantes na contemporaneidade, que podem, a partir de um mesmo contexto, representar a manutenção de um status quo ou expressar as diferenciações que a “semântica amorosa” (COSTA, 2005) assume a partir de distintas subjetividades.

Assim, dentro dessas novas possibilidades de expressões afetivas, a representação do amor romântico na velhice ganha espaço, desfazendo algumas concepções e (re) construindo modelos simbólicos. Outros olhares sobre os relacionamentos amorosos vêm sendo apresentados entre corpos envelhecidos, olhares esses que relegam a segundo plano a busca descomedida pela manutenção do corpo perfeito e a apreensão de um olhar masculino, ressaltando trocas afetivas profícuas e diferenciadas formas de manifestações do desejo.

No que se refere especificamente ao cinema brasileiro contemporâneo, especialmente a partir do período da Retomada, evidencia-se um momento propício à representação dessas outras possibilidades de relações afetivas no envelhecer. Como se verá a seguir, isso se deve, sobretudo, ao destaque dado aos dramas individuais nas narrativas cinematográficas, especialmente a partir do surgimento de um “novo cinema brasileiro”.

\subsection{A narrativa íntima no cinema da Retomada}

A partir da década de 1970, o cinema brasileiro retraça novos caminhos, marcado por um momento de intensa repressão e censura. Muitos representantes do movimento do excinema novo buscaram se adaptar às novas circunstâncias políticas e econômicas brasileiras e, negligenciados na política de financiamento estatal desenvolvida pelo Instituto Nacional de Cinema - INC -, desenvolveram uma estrutura de produção e distribuição nacional de filmes: a Difilm, o que acabou sendo um projeto piloto para que o Estado marcasse presença no mercado cinematográfico nacional, por meio da Embrafilme.

Assim, se os ex-cinemanovistas já eram detentores de um prestígio que levava à hegemonia cultural, esse controle estatal os levou a uma hegemonia de elite. Passaram então a falar em nome de toda a classe cinematográfica. A Embrafilme tornou-se a maior produtora e distribuidora do país, investindo em eventos, festivais, pesquisa e publicações.

Os ideais do movimento do ex-cinema novo, que direcionavam para um cinema consciente e preocupado com o homem brasileiro e seus conflitos sociais, permearam de certa forma o discurso cinematográfico estatal durante esse período, que se voltou em grande parte 
para as concepções sobre ser brasileiro, para os valores nacionais, a memória cultural e a identidade nacional (CALDAS; MONTORO, 2006). Manteve-se então, nesse período, certo cunho político-social que permeava algumas produções da época.

Portanto, durante a revolução estética e narrativa na forma do filme, ocorrida nos anos 60 e 70, a preocupação era com a construção de um cinema antiimperialista, independente e alternativo, destinado à provocação e militância, e cujo sujeito das revoluções era definido implicitamente como masculino: "em geral produzido por homens, os filmes terceiromundistas não expressaram interesse por uma crítica feminina do discurso nacionalista [...] as lutas das mulheres no campo “privado” ganham pouca atenção”. (SHOHAT; STAM, 2006, p. 404).

Tanto no período de apogeu do Cinema Novo, quanto nas primeiras décadas do cinema brasileiro contemporâneo, nota-se que as questões relacionadas às lutas políticas das mulheres e dos idosos aparecem timidamente, encontrando-se aqui, sobretudo, um cinema centrado em conflitos sociais mais amplos (tal como a pobreza) e em uma preocupação em retratar os problemas relacionados ao colonialismo cultural e ao imperialismo exercidos sobre os países de "terceiro-mundo”.

O “drama de família” (CALDAS; MONTORO, 2006) e as relações amorosas aparecem, porém, em alguns filmes produzidos nessas épocas, como Matou a família e foi ao cinema (1969), de Júlio Bressane, dividido em vários episódios que focam a agressão doméstica e o crime passional; na tragicomédia Guerra Conjugal (1974), de Joaquim Pedro de Andrade, que realiza uma crítica ao machismo da comédia erótica, e em especial no filme Chuvas de Verão (1977), de Carlos Diegues, que retrata a vida de Afonso (Jofre Soares), um recém aposentado de setenta anos, morador de um subúrbio do Rio de Janeiro.

Após a sua aposentadoria, Afonso passa a se envolver em problemas familiares e com amigos, iniciando também uma bonita relação de amizade e amor com a sua vizinha Isaura (Míriam Pires). A obra se destaca por representar formas diferenciadas de vivência na velhice. Assim, Afonso, que a princípio via a aposentadoria como um marco temporal a partir do qual o ócio se estabeleceria, relacionando-a a um período de perdas (da sociabilidade, do trabalho, da saúde), vai, no decorrer do filme marcado por acontecimentos inusitados, descobrindo o envelhecer como um momento de vitalidade e, também, de construção de novas afetividades.

Em um momento em que a questão do envelhecer não se fazia tão presente nas mídias e que o apagamento das fronteiras entre as faixas etárias e a criação de mercados de consumo, 
tal como colocado por Debert (1999a), aparecia ainda de forma incipiente, ou seja, quando ainda se tinha uma imagem estigmatizante do velho, a representação das relações familiares e afetivas em alguns filmes da década de 1970 apresentam-se como pontos contradiscursivos, evidenciando que “[...] diversidade sempre tivemos. O que talvez seja característico da época atual é o fato de a diversidade ter sido transformada em um valor” (XAVIER, 1998, p.84), seja na propagação pela mídia de estilos de vida considerados adequados, seja em uma maior abertura para a expressão de novas polaridades identitárias.

É esse espaço que ganha força, sobretudo, a partir do período da Retomada do cinema brasileiro. Diferentemente do Cinema Novo, o “novo cinema brasileiro" nasceu sem manifesto ou qualquer característica coletiva de movimento (MATTOS, 1998, p.48). Ao contrário, evidenciou-se na justaposição de individualidades, captando a fragmentação da sociedade contemporânea, a diversidade e o pluralismo estético. Aqui o cinema brasileiro não se constrói em termos de oposições, contra algo. Ao contrário, desfaz toda a oposição. Representa o ecletismo, as formas diferenciadas que dissolvem as questões políticas até então apresentadas pelos ideais cinemanovistas.

As opções narrativas recaem, então, nos conflitos familiares e amorosos. O cinema se fortalece como um cinema da intimidade, onde as preocupações sociais herdadas do Cinema Novo se dissolvem nos dramas individuais. Assim, as paisagens como o sertão, as favelas e os subúrbios, cenários presentes em importantes obras a partir dos anos 60 , quando aparecem no “novo cinema brasileiro” apresentam-se como “jardins exóticos” (BENTES, 2001), funcionando como plano de fundo para os conflitos individuais que se estabelecem nas narrativas.

É a partir dessa perspectiva que o cinema pode apresentar-se dentro de possibilidades de representação de outras identidades, que emergem contrárias aos ideais hegemônicos. Os dramas individuais se transformam, nesse sentido, em um espaço onde novas formas de ser e pensar podem ser representadas. Por meio dos conflitos individuais, do drama familiar e dos afetos, o "novo cinema brasileiro” “[...] incorpora na vida de cada indivíduo todos os componentes existentes: o político, o social, o econômico e o pessoal, no seu cinema dramático, romântico e de percepção individual” (CALDAS; MONTORO, 2006, p.295). As intimidades aparecem, então, como um lugar onde o político ressurge e se reconstrói, em forma de transgressões a comportamentos normatizados. Um lugar onde se pode voltar os 
olhos para as novas práticas em relação ao envelhecimento, olhar muitas vezes negligenciado nos períodos anteriores do cinema brasileiro.

Em um momento histórico no qual a sociedade elegeu o individual em detrimento ao coletivo e ao social, é que o político acontece no privado, nos espaços da casa e nos relacionamentos afetivos. "Dito de outra forma, o cinema dos anos 90 é ao mesmo tempo social, pessoal, político e intimista, sem escolas, doutrinas ou alinhamentos ideológicos. É um cinema pluralista, na mais profunda concepção do termo” (CALDAS; MONTORO, 2006, p. 295).

Assim, contrapondo-se às representações do novo cinema brasileiro que reforçam, na narrativa íntima, comportamentos hegemônicos referentes ao envelhecimento e ao amor - tal como Divã (2009), de José Alvarenga Júnior e baseado na obra literária de mesmo nome de Martha Medeiros - têm-se filmes que transgridem esses comportamentos, tal como $O$ outro lado da Rua (2004), de Marcos Bernstein.

Se em Divã destaca-se a protagonista Mercedes (Lilia Cabral), uma mulher de 40 anos que, recém-separada, rende-se à lógica dos relacionamentos superficiais e descartáveis, em $O$ Outro Lado da Rua tem-se como personagem principal Regina (Fernanda Montenegro), uma aposentada de 65 anos que encontra uma alternativa à solidão em um programa para "terceira idade”, por ela mesma denominado de “disque-denúncia profissional”. Regina vive à procura de pequenos delitos em sua vizinhança para denunciá-los a polícia, envolvendo-se, dessa forma, com Camargo (Raul Cortez). Nesse envolvimento, o casal acaba redescobrindo a amizade, o amor e o desejo, demonstrando que novas possibilidades de afetos entre os corpos envelhecidos surgem também a partir da cumplicidade, da troca de experiências vividas e da aceitação corporal em relação aos traços do envelhecimento.

Assim, a partir desse breve panorama sobre o cinema brasileiro da Retomada especialmente no que se refere à representação das relações afetivas na velhice - aprofundase, neste momento, nas reflexões sobre o curta-metragem Olhos de Ressaca.

Para tal, definiu-se como metodologia a Análise Fílmica, tendo como foco o estudo dos elementos de linguagem explícitos (figurino, cenário, texto, e demais recursos que constroem explicitamente a imagem do personagem) e dos elementos de linguagem implícitos (iluminação, sons, ângulos de câmera e enquadramentos) incorporados aos filmes. 
Segundo Benjamin (2000, p.244), a linguagem cinematográfica aprofunda a percepção, substituindo o espaço no qual o homem age conscientemente por um espaço onde sua ação é inconsciente:

É nesse domínio que a câmera penetra, com todos seus meios auxiliares, com subidas e descidas, seus cortes e suas separações, suas extensões de campo e suas acelerações, ampliações e reduções. Pela primeira vez, ela nos abre a experiência de um inconsciente visual, assim como a psicanálise nos fornece a experiência do inconsciente instintivo (BENJAMIN, 2000, p.244).

Busca-se, assim, investigar como a linguagem cinematográfica, em suas especificidades, pode (re)construir a realidade afetiva dos(as) mais velhos(as), trabalhando no sentido de detectar os códigos cinematográficos utilizados nas obras (tipos de enquadramentos, de tomadas de câmera, de pontos de vistas) e ressignificá-los, tendo em vista o cinema como um espaço de manifestação simbólica de práticas sociais.

É nesse sentido que optou-se pelas obras de Casetti e Di Chio (2007) e Vanoye e Goliot-Lété (2005) para nortear a análise fílmica desenvolvida neste trabalho.

[...] Só quando se articulam a um conteúdo os componentes expressivos do filme adquirem uma razão de existir. [...]O conteúdo e a expressão formam um todo. Apenas sua combinação, sua associação íntima é capaz de gerar a significação (VANOYE; GOLIOT-LÉTÉ, 2005, p.41-42).

Considerando, assim, que os filmes selecionam e organizam elementos em relações complexas com o mundo real é que se faz importante incluir a Análise de Discurso como aporte metodológico complementar à Análise Fílmica.

Segundo Orlandi (2007), o discurso não se trata de mera transmissão de informação, já que o funcionamento da linguagem põe em relação sujeitos e sentidos, afetados pela língua e pela história. “A análise do discurso visa compreender como os objetos simbólicos produzem sentidos, analisando assim os gestos de interpretação que ela considera como atos do domínio simbólico, pois eles intervêm no real do sentido.” (ORLANDI, 2007, p.26).

Dessa forma, procura-se (re) significar os elementos cinematográficos em seus aspectos implícitos e explícitos, valendo-se também da Análise de Discurso, para que se possa identificar a encenação de novos discursos fílmicos em relação às práticas sociais e culturais relativas ao envelhecimento.

A intenção é estabelecer conjecturas em relação ao que o filme diz, tendo em mente que os produtos cinematográficos são também produtos culturais e, portanto, estão inseridos 
dentro de um determinado contexto sócio-histórico. Busca-se assim uma interpretação, sobretudo, sócio-histórica, evidenciando que os filmes relacionam-se a outros setores de atividade da sociedade que os produz.

\subsection{Vera e Gabriel: memórias de uma trajetória amorosa}

Dirigido por Petra Costa, o curta-metragem Olhos de Ressaca foi produzido no início de 2009, quando, a convite da família de Vera e Gabriel, os jornalistas Nathália Ziemkiewicz e Camilo Vannuchi estiveram na fazenda do casal, em Minas Gerais, para acompanhar de perto um pouco dos seus quase 60 anos de história de amor. O objetivo era eternizar a história em um livro - Vera e Gabriel 60 quilates: a arte de encomendar vestidos de bolinhas $e$ semear diamantes -, lançado dois meses após a visita à fazenda. Durante essa mesma viagem, a diretora - uma das netas de Vera e Gabriel -, gravou depoimentos com as principais lembranças dos avós, enquanto a conversa com a escritora e o jornalista corria de forma descontraída, já que o livro deveria ser uma surpresa para o casal.

Foi a partir desses depoimentos, entremeados por antigos arquivos de vídeo e registros fotográficos, que Petra Costa - com a ajuda dos irmãos Eryk Rocha e Ava Rocha ${ }^{3}$, responsáveis respectivamente pela fotografia e montagem do curta - conseguiu transpor para as telas a trajetória amorosa de Vera e Gabriel dentro de uma atmosfera onírica e poética, capaz de fazer o espectador refletir sobre os limites entre realidade e ficção na representação do amor romântico.

O que se destaca no filme é uma tendência intimista, em que a linguagem cinematográfica trabalha no sentido de aproximar o espectador das experiências narradas, situando-o em um espaço onde a representação do imaginário mescla-se à representação realista e objetiva dos fatos. Essa tendência intimista reflete-se, também, na escolha da forma fílmica curta que, segundo Vanoye e Goliot-Lété (2005), aparece não só como uma alternativa

\footnotetext{
${ }^{3}$ Eryk Rocha e Ava Rocha são filhos do diretor Glauber Rocha. Nascido em Brasília, em 1978, Eryk viveu com a mãe em Bogotá entre os 15 e 20 anos de idade. Graduou-se em Cinema e Televisão na Escola de San Antonio de losBaños, em Cuba, produzindo, em 2002, seu primeiro documentário se longa-metragem :Rocha que Voa. O filme foi premiado no Cinesul e selecionado para os festivais internacionais de Locarno, Veneza, Montreal e Havana. Produziu também os documentários Intervalo Clandestino, em 2006, e Pachamama, em 2008, e o longa de ficção Transeunte, em 2010. Cantora e compositora, Ava Rocha nasceu em 1979, no Rio de Janeiro. Também atua no cinema como montadora, diretora e desenhista sonora. Cantou nas trilhas sonoras dos filmes Diário de Sintra, de Paula Gaitán; Kynemas, de Pedro Paulo Rocha; Amaxon, de José Sette; Miragem em Abismo e Laminadas Almas, de Eryk Rocha. Participou, como cantora e atriz, no espetáculo Os Sertões, montagem de Zé Celso e no , e nos filmes Transeunte, de Eryk Rocha, Jardim Atlântico de William Cubits e Tubilustrium, de CordéliaFaurneux. Em 2008, formou a banda AVA.
} 
para as primeiras obras de um cineasta, como também para produzir um impacto de forma mais evidente que os longas-metragens, já que a apreensão dos elementos narrativos, discursivos, dramáticos e rítmicos dos curtas não tem tempo de ser aprofundada em uma história ou nos mecanismos de identificação com os personagens. Assim, se o filme curto deve se oferecer à percepção de forma mais rápida e aguda, Olhos de Ressaca cumpre sua função na medida em que transpõe a linguagem poética para o cinema, evidenciando as emoções em torno da breve história narrada e aguçando sensações no espectador.

A projeção inicia-se com a imagem da sombra do casal estampada em um chão por onde caminham. O que se ouve é algo parecido com o barulho das ondas quebrando na areia. Não se sabe exatamente onde estão, nem este lugar é mostrado em sua totalidade após este momento. Interessa mais a intimidade demonstrada no subseqüente big close das mãos que acariciam e da bela tonalidade dos cabelos grisalhos de Vera. Interessa mais a delicadeza dos beijos trocados entre o casal, que surgem em close, seguidos do olhar da protagonista, que ocupa toda a tela. Gabriel cita então um trecho de Dom Casmurro, de Machado de Assis.

GABRIEL: Traziam não sei que fluido misterioso e enérgico, uma força que arrastava para dentro como a vaga que se retira da praia nos dias de ressaca [...] Para não ser arrastado, agarrei-me às outras partes vizinhas, mas tão depressa buscava as pupilas, a onda que saia delas vinha crescendo, cava e escura, ameaçando envolver-me, puxar-me e tragar-me.

A partir desse momento, é possível compreender a função narrativa abstrata do som over $^{4}$ percebido ao inicio da projeção. O barulho do mar tem aqui uma função simbólica, refletindo-se no trecho agora citado por Gabriel e ligando-se às imagens das ondas do mar, do céu e de uma antiga foto de Vera, que surgem na tela logo após o big close dos olhos da protagonista. Gabriel revela que - assim como dizia Machado de Assis sobre Capitu - Vera tinha olhos de ressaca que o atraiam. A expressão criada pelo escritor, que aparece neste momento ao centro da tela, dá então título ao curta, simbolizando os sentimentos que envolvem o casal e introduzindo o espectador na história de amor que será narrada.

Ao combinar texto literário, imagens e som extra-diegéticos e planos em close e big close, Olhos de Ressaca consegue adentrar a intimidade de Vera e Gabriel, transformando o que poderia ser apenas um relato em uma experiência onírica e afetiva. O filme é inteiramente narrado pelo do casal, alternando os depoimentos de um e de outro e

\footnotetext{
${ }^{4}$ Casetti e Di Chio (2007) definem o som over como sendo aquele proveniente de uma fonte não diegética e que serve para criar efeitos mais amplos do que os proporcionados pela imagem.
}

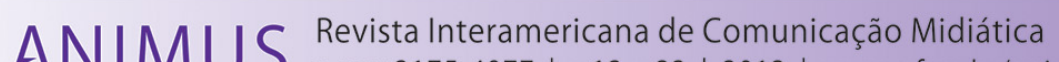

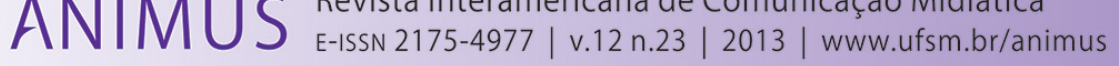


entremeando antigos vídeos e fotografias de família. O casal passeia pelas lembranças divagando sobre a família, as diferenças de personalidade entre os dois e apresentando suas visões sobre o amor e a morte na velhice.

A montagem em Olhos de Ressaca funde os antigos vídeos e fotografias de Vera e Gabriel, às paisagens do céu e do mar e às imagens atuais do casal. Trabalha assim uma mistura entre objetividade (os fatos narrados pelos protagonistas) e subjetividade (as impressões, lembranças e sentimentos aos fatos associados), atenuando os limites entre passado e presente. Recorrendo a Elias (1998), pode-se dizer que o filme confirma, na representação da história de Vera e Gabriel, a capacidade do homem de considerar concomitantemente o que se produz em sucessão, evidenciando a presença simultânea dessas duas dimensões da experiência humana.

Passado e presente não são, portanto, instâncias fixas, como sugere a padronização social do tempo determinada pelos relógios e calendários. O passado constrói continuamente o presente, que caminha e se solidifica na rememoração das lembranças e na transformação dos sentimentos que perduram com o passar do tempo. Assim é o amor de Vera e Gabriel, a despeito de todas as limitações e dificuldades que chegam com a velhice. Os depoimentos realizados ao final da projeção expressam essa relativização das perdas advindas com a passagem do tempo, sobretudo por meio da valorização da memória.

VERA - Algumas vezes eu tenho certas dificuldades, de me movimentar, de dizer algumas palavras, de cantar, a voz não sai... Eu vejo que isso é a idade que ta... mudando.

Mais tarde, Vera continua:

VERA - Mas em compensação, a gente conhece mais coisas, a gente distingue melhor as aproximações das pessoas que tem mais carinho com a gente. Essa percepção das coisas que nos envolvem aumenta com... com a idade. Uma delas é essa aqui, ó (imagem do casal de mãos dadas em um balanço)... mas isso sempre foi assim, isso é muito importante. Não é qualquer pessoa que tem momentos assim, como eu tenho com ele. Que a gente sente o apoio um do outro, sem precisar falar nada, só de cruzar o olhar... GABRIEL - É mesmo. VERA - Não é! É a melhor coisa do mundo! Nós não temos mais aquela paixão do início, né... a gente tem ainda aquele carinho um com o outro, e é um carinho mesmo. Assim, puro, muito suave, muito agradável, que dá estímulo pra gente de continuar tudo. A gente não sabe viver separado mais não. Nossa vida é toda entrelaçada mesmo.

\section{ANIMUS Revista Interamericana de Comunicação Midiática} E-ISSN 2175-4977 | v.12 n.23 | 2013 | www.ufsm.br/animus 
Assim, o tempo corre, mas o passado está vivo e presente na história do casal. Memória e projeto de vida se entrelaçam, demonstrando, conforme colocado por Barros (2006), a construção de uma outra dimensão do tempo, “o tempo da biografia”, percebido como uma trajetória capaz de unir passado, presente e futuro.

Segundo a autora, as lembranças são construções do presente, que feitas e refeitas nas relações sociais, constituem as experiências de vida dos mais velhos que são por eles apresentadas como ganhos na velhice. A simultaneidade expressa no "tempo da biografia" (que, por meio do passado, constrói o presente e projeta o futuro) substitui assim a idéia de fronteiras etárias (e com elas as visões estigmatizadas da velhice) indicada pelo tempo cronológico, retirando a ênfase do envelhecimento como um momento de decadência física e de maior aproximação da morte e reforçando realizações pessoais e prazeres possíveis nessa fase da vida.

Relativizar as perdas associadas ao envelhecer significa então, para Vera e Gabriel, entender a velhice não como uma etapa sucessória carregada de estigmas corporais e sociais, mas sim como um processo de constante transformação em que o passado permanece presente por meio dos sentimentos verdadeiros. A memória ressignifica, assim, o amor, afirmando-o como potência libertadora e transgressora.

\subsection{Diálogos afetivos: um outro amor é possível}

A partir dos conceitos de Negri (2001) evidencia-se, em Olhos de Ressaca, a existência de um "valor-afeto", ou de uma "potência de agir" que move as sociedades contemporâneas. Segundo o autor, os afetos constituem o cerne de todas as realizações humanas, determinando também uma potência expansiva, um "não-lugar” que a economia, a política, os discursos autoritários não conseguem controlar por completo. As afetividades funcionam, nesse sentido, como potências libertadoras, podendo promover mudanças sociais e o exercício de práticas que se contrapõem às hegemônicas.

Assim, ao narrar, de forma experimental, a trajetória de vida de um casal que, a despeito das limitações físicas e dos sinais corporais adquiridos com o envelhecimento, reafirma e ressignifica o amor, o curta ressalta essa importância dos afetos como "potências expansivas” na subversão de comportamentos adequados aos mais velhos, especialmente à mulher (seja em relação à visão que relaciona a velhice à solidão e invisibilidade, seja em 
relação às novas práticas de consumo que negam o envelhecer corporal por meio de constantes intervenções estéticas).

Indo além, se pode dizer que essa visão libertária das afetividades percebe-se também, no filme, por meio da dualidade/complementaridade masculino/feminino, que infringe os padrões normatizados em relação aos gêneros, entendendo-os como instâncias que contém uma a outra. Sobre suas personalidades, o casal relata:

VERA: Eu gostava muito de andar descalça, detestava colocar sapato. Chutava bola, a gente chamava de futebol, mas era só chutar a bola. GABRIEL: Eu era chorão, mas evitava, tinha vergonha, né. Por que os meninos gozavam os chorões, eles falavam: oh, manteiga derretida, chorão. Então a gente aprendia a reprimir.

Vera e Gabriel vivem então feminilidades e masculinidades diferentes das hegemônicas. Como mais tarde colocado pela protagonista, Vera se considera mais impetuosa e realista, enquanto vê Gabriel como um homem distraído, sensível e sonhador. O curta evidencia essas diferenciadas manifestações de gênero, ressaltando a sensibilidade e a emotividade presente no masculino, e a objetividade e determinação que emergem do feminino. A própria forma de construção narrativa remete o espectador a essa complementaridade, dando à voz feminina uma narração mais realista dos fatos, enquanto a voz masculina aparece na maior parte das vezes expressando sua versão sobre os acontecimentos por meio de canções, poesias e trechos literários.

Portanto, a relação entre os gêneros em Olhos de Ressaca se dá de forma dialógica, onde as práticas patriarcais que submetem a mulher ao olhar masculino são ressignificadas, dentro do casamento, apontando para uma possibilidade de libertação feminina no núcleo doméstico. Conforme colocado por Negri (2001), “A vida é uma prisão quando não a construímos e quando o tempo da vida não é apreendido livremente.” (NEGRI, 2001, p.21). Apreender o tempo da vida livremente significa, para o autor, viver as paixões positivas, que libertam as relações e que determinam a alegria. O amor construído entre o casal parece então liberar Vera das “prisões sociais” femininas, apresentando possibilidades de realização no casamento diferentes das institucionalizadas.

É nesse sentido que também se apresenta no filme a seqüência de imagens na qual Gabriel se barbeia enquanto Vera faz sua maquiagem, o que serve para confirmar, na 
referência ao envelhecer, a visão complementar do feminino/masculino já evidenciada na obra. Na sequência em questão, a escolha dos enquadramentos íntimos e da iluminação clara reflete ainda uma aceitação das marcas corporais, libertando o feminino da preocupação em esconder traços do envelhecimento. As imagens apresentadas na cena combinam-se então ao relato da personagem sobre as diferenças de personalidade entre o casal.

VERA: Eu sou mais impetuosa, ele é mais calmo. Eu sou mais...real, ele mais sonhador. Ele chega sempre atrasado, eu chego sempre adiantada. E fica aí se deliciando com as obras de Castro Alves, Machado de Assis.

Assim, embora vivendo feminilidade e masculinidade distintas das convencionais, a cena comprova que Vera e Gabriel não se perdem em suas essências. Ao cuidar de sua aparência ao mesmo tempo em que, em off, relata ser mais realista (característica tida convencionalmente como masculina) enquanto Gabriel mais sonhador (característica tida convencionalmente como feminina), a protagonista demonstra que existem outras formas de viver a feminilidade, inclusive longe dos excessos do corpo medicalizado, já que a sua vaidade não oculta os sinais do tempo deixados em seu corpo. O amor de Vera e Gabriel, diferentemente da freqüente transitoriedade dos amores contemporâneos, segue resistindo ao tempo, às rugas e aos cabelos brancos.

Ao divagarem sobre as questões de vida/envelhecimento/morte - Vera de forma objetiva e Gabriel de maneira poética - o casal também imprime visões diferenciadas sobre o envelhecer, evidenciadas ao final da projeção na referência ao poema Mocidade e Morte, de Castro Alves, por meio do qual, segundo Gabriel, é possível ver o quão bonita é a mocidade.

GABRIEL: Oh, eu quero viver. Beber perfume na flor silvestre que embalsama os ares, Ver minha alma adejar pelo infinito, Qual branca vela na amplidão dos mares, No seio da mulher há tanto aroma, Nos seus beijos de fogo há tanta vida, Árabe berrante, Vou dormir à tarde à sombra fresca da palmeira erguida.

Indo além do que é narrado no filme, o poema de Castro Alves ainda diz:

[...]Mas uma voz responde-me sombria:

Terás o sono sob a lájea fria.

Morrer... quando este mundo é um paraíso,

E a alma um cisne de douradas plumas:

Não! o seio da amante é um lago virgem...

Quero boiar à tona das espumas[...]. 
(ALVES, 2002, p. 60)

É nesse trecho do poema que se percebe o que Gabriel denomina de “angústia de Castro Alves”, em outras palavras, o medo do envelhecer diante de toda a beleza da vida e da juventude. Contudo, diferentemente do poeta, o protagonista vê a morte como algo aceitável. Para ele, o medo existe, mas, aos 80 anos, deve ser enfrentado e encarado tendo em vista a morte como algo natural. É nesse momento final da projeção, e intercalando as falas dos protagonistas, que Vera corrobora a visão de Gabriel no já mencionado depoimento sobre a relativização das perdas na velhice por meio da valorização da memória.

O texto de João Guimarães Rosa, em Grande sertão: veredas, citado pelo protagonista ao final da projeção enquanto os créditos do filme surgem na tela - combinado à imagem do casal em um balanço - deixa a mensagem de que a vida conserva e ao mesmo tempo transforma os sentimentos verdadeiros. A alegria juvenil permanece vívida, mesmo com o passar do tempo. Vera e Gabriel não precisam rivalizar constantemente com o envelhecimento e com a aparente proximidade da morte que ele traz, afinal, eles renascem a cada dia na poesia do amor que souberam cultivar.

GABRIEL: Ô senhor...Mire veja: o mais importante e bonito, do mundo, é isto: que as pessoas não estão sempre iguais, ainda não foram terminadas mas que elas vão sempre mudando. Afinam ou desafinam. Verdade maior. É o que a vida me ensinou. Isso que me alegra, montão (trecho de Grande sertão: veredas, de João Guimarães Rosa).

\section{CONSIDERAÇÕES}

Ao transitar por algumas facetas do discurso amoroso, construídas ao longo do tempo pelos agentes sociais e (re) produzidas pelas narrativas audiovisuais, este artigo procurou demonstrar a emergência de novas polaridades sobre as identidades midiáticas que representam as relações afetivas na velhice, centrando-se especialmente na cinematografia brasileira contemporânea.

Essas novas polaridades nascem, sobretudo, a partir da Retomada do cinema brasileiro, quando encontram um momento adequado não só para a representação das intimidades, do amor e das relações familiares, como também para a expressão de discursos transgressores a respeito dessas representações. Transpor as relações romântico-afetivas na 
velhice para as telas de cinema apresentou-se aqui como uma possibilidade de atribuir novos significados ao ideário do amor romântico (convencionalmente patriarcal) e à lógica do consumo imediatista, que tende a rejeitar o velho, a memória e a solidificação dos relacionamentos afetivos.

Assim, no curta escolhido para acompanhar as reflexões realizadas neste artigo, o passado é restituído, ressignificado e valorizado, tendo em vista um amor que se contrapõe à frequente superficialidade dos relacionamentos contemporâneos. Se o advento das novas tecnologias e os avanços medicinais e farmacológicos tem apontado para uma recusa do envelhecer, tornando também as relações amorosas descartáveis na medida em que não mais oferecem gratificações emocionais imediatas, Olhos de Ressaca demonstra que é possível subverter essa lógica no exercício de um amor que se apropria do passado para ressignficar as experiências do presente e solidificar as afetividades.

Essa solidificação acontece, porém, a partir de uma constante mudança. Surge de um amadurecimento emocional que faz emergir novas facetas amorosas a partir da conservação de um "eu” que evolui no diálogo com o outro, que se abre para as trocas afetivas não convencionais. Muda-se (ou morre-se) com o tempo, e a cada dia, mas para renascer mais forte e (re) descobrir sentimentos que enriquecem e libertam as relações, que dão sentido à vida.

É essa possiblidade de libertação que o filme ressalta, sobretudo, na transformação das relações constituídas de afetos, edificando assim uma percepção a respeito da velhice que remete à vida, à alegria, ao romantismo e aos ganhos possíveis no envelhecer. É na representação do amor romântico de Vera e Gabriel que a poesia ofusca a morte e dá sentido à vida. No curta, as afetividades construídas ao longo do tempo apresentam-se, nas palavras de Negri (2001), como "potências expansivas” responsáveis também por transgredir os papéis culturalmente e historicamente destinados ao feminino, libertando-o das orientações excessivas do culto ao corpo (e da submissão a um olhar patriarcal), e demonstrando uma dualidade/complementaridade feminino/masculino dentro do casamento.

Por fim, é esse entendimento de uma "potência expansiva” no exercício dos afetos que traz em si um caráter transgressor, transformando o amor em infração obscena aos comportamentos efêmeros característicos de uma cultura de consumo.

Tudo o que é anacrônico é obsceno. Como divindade (moderna), a História é repressiva, o Histórico proíbe-nos de ser não atuais. Do passado, apenas suportamos a ruína, o monumento, o mau gosto, o retrógrado, que é 
divertido; reduzimo-lo, este passado, à sua única assinatura. O sentimento de amor está fora de moda e essa moda nem como espetáculo pode ser recuperada: o amor sucumbe fora do tempo próprio; nenhum sentido histórico, polemico, lhe pode ser dado: é nisso que reside a sua obscenidade (BARTHES, 2001, p. 207).

É nessa possibilidade de afirmação contradiscursiva do amor, demonstrada aqui na análise do curta-metragem Olhos de Ressaca, que as narrativas cinematográficas apresentamse, então, como resposta aos conflitos humanos, às questões de vida/envelhecimento/morte, à oposição binária masculino/feminino. Em meio à luta frenética por uma felicidade patriarcal, consumista, superficial e descartável, as novas manifestações simbólicas das afetividades permitem o despertar de um olhar interior e reflexivo sobre os próprios (e verdadeiros) anseios e desejos, sobre os possíveis diálogos com o outro, sobre a vida e a finitude. É esse olhar, ao mesmo tempo ativo e contemplativo, sereno e inquieto, que permite a abertura de caminhos mais sólidos para que se possa compreender os vazios existenciais inerentes à alma humana.

\section{REFERÊNCIAS}

ALVES, Castro. Espumas Flutuantes. Porto Alegre: L\&PM, 2002.

BARROS, Myriam Lins de Barros. Autoridade e afeto: vós, filhos e netos na família brasileira. São Paulo, SP: Jorge Zahar Editor, 1987.

BARROS, Myriam Moraes Lins de. Trajetória dos estudos da velhice no Brasil. In: Sociologia, Problemas e Práticas, n.52, p.109-132, 2006.

BARTHES, Roland. Fragmentos de um discurso amoroso. Lisboa, Portugal: Edições 70, 2001.

BENJAMIN, Walter. A obra de arte na época de sua reprodutibilidade técnica. In. LIMA, Luiz C. (Org.). Teoria da cultura de massa. 2.ed. Rio de Janeiro: Paz e terra, 1978. p.205240.

BENTES, Ivana. Cosmética da fome marca cinema no país. In: Jornal do Brasil, 8 julho, 2001.

CALDAS, Ricardo Waherndorff; MONTORO, Tânia. A evolução do cinema brasileiro no Século XX. Brasília, DF: Casa das Musas, 2006.

CASETTI, Francesco. DI CHIO, Frederico. Cómo analizar um film. Tradução de Carlos Losilla. Barcelona: Paidos, 2007. 
COSTA, Sérgio. Amores fáceis: romantismo e consumo na modernidade tardia. In: Novos estudos - CEBRAP, São Paulo, n.73, Nov. 2005.

DEBERT, Guita Grin. A reinvenção da velhice: socialização e processos de reprivatização do envelhecimento. São Paulo, SP: Editora da Universidade de São Paulo, FAPESP, 1999a.

ELIAS, Norbert. Sobre o tempo. Rio de Janeiro: Jorge Zahar Ed., 1998.

GUEDES, Dilcio; ASSUNÇÃO, Larissa. Relações amorosas na contemporaneidade e indícios do colapso do amor romântico (solidão cibernética?). In: Revista Mal estar e subjetividade, Fortaleza, v.6, n.2, set, 2006.

MARTINO, Luiz C. Elementos para uma epistemologia da comunicação. In: NETO, A.F.;PRADO,J.L.A.;PORTO,S.D. (Org). Campo da Comunicação: caracterização, problematizações e perspectivas. João Pessoa: Editora Universitária/UFPB,2001. p.51-75.

MATTOS, Carlos Alberto. Dramaturgias do cinema brasileiro: Sinais de vida. In: Cinemais: revista de cinema e outras questões audiovisuais, n. 11, p.47-78, Rio de Janeiro, maio/junho 1998.

MONTORO, Tania. Velhices e envelhecimentos: dispersas memórias na cinematografia mundial. In: MENDONÇA, M.L.M.(Org). Mídia e Diversidade Cultural: experiências e reflexões. Brasília: Casa das Musas, 2009. p. 191-205.

NEGRI, Toni. Exílio: seguido de valor e afeto. São Paulo: Iluminuras, 2001.

NEVES, Ana Sofia Antunes. As mulheres e os discursos genderizados sobre o amor: a caminho do "amor confluente" ou o retorno ao mito do "amor romântico". In: Estudos feministas, Florianópolis, 15(3): 336, p. 609-627, set./dez, 2007.

ORLANDI, E.P. Análise de discurso: princípios e procedimentos. Campinas: Pontes, 2007.

SHOHAT, Ella; STAM, Robert. Crítica da imagem eurocêntrica: multiculturalismo e representação. São Paulo: Cosac Naify, 2006.

VANOYE, Francis; GOLIOT-LÉTÉ, Anne. Ensaio sobre a análise fílmica. Campinas, SP: Papirus, 2005.

XAVIER, Ismail. Inventar narrativas contemporâneas. In: Cinemais: revista de cinema e outras questões audiovisuais, n. 11, p.47-78, Rio de Janeiro, maio/junho 1998.

\section{REFERÊNCIAS CINEMATOGRÁFICAS}

CHUVAS de Verão. Direção: Carlos Diegues. Produção: Philippa Campbell, 1977, 1DVD (92min).

DIVÃ. Direção: José Alvarenga Júnior. Produção: Total Entertainment, 2009. 1DVD (93min). 
GUERRA Conjugal. Direção: Joaquim Pedro de Andrade, 1974. 1 DVD (73min).

MATOU a família e foi ao cinema. Direção: Júlio Bressane. Produção: Belair Filmes e Júlio Bressane, 1969. 1DVD (80min).

O OUTRO lado da Rua. Direção: Marcos Bernstein. Produção: Marcos Bernstein e Kátia Machado, 2004. 1DVD (97min).

OLHOS de Ressaca. Direção: Petra Costa. Produção: Petra Costa, 2009. 20min. Disponível em: <http://www.portacurtas.com.br/filme.asp?cod=8914>. Acesso em: 20. dez. 2010.

Original recebido em: 30/04/2013

Aceito para a publicação em: 20/07/2013

Clarissa Raquel M. D. S.

Mestre em Comunicação pela Universidade Federal de Goiás - Linha de Pesquisa: Mídia e Cultura. Especialização em Planejamento e Gestão de Eventos pela Pontifícia Universidade Católica de Goiás (2009). Graduação em Comunicação Social - Publicidade e Propaganda pela Universidade Federal de Goiás (2006).

Maria Luiza M. de Mendonça

Possui graduação em Relações Públicas pela Universidade de Brasília (1977), mestrado em Comunicação pela Universidade de Brasília (1981) e doutorado em Ciências da Comunicação pela Universidade de São Paulo (1999). Pós-doutorado em comunicação audiovisual na Universidad Autónoma de Barcelona (2007). Atualmente é professora associada da Faculdade de Comunicação da Universidade Federal de Goiás. Professora do curso de mestrado em comunicação da UFG. 